\title{
Labyrinthe
}

$6 \mid 2000$

Numéro 6

\section{L'héraldique balzacienne : mise en perspective}

\section{Laurent Ferri}

\section{OpenEdition}

Journals

Édition électronique

URL : http://journals.openedition.org/labyrinthe/410

DOI : 10.4000/labyrinthe.410

ISSN : 1950-6031

Éditeur

Hermann

Édition imprimée

Date de publication : 1 juin 2000

Pagination : 121-123

\section{Référence électronique}

Laurent Ferri, «L'héraldique balzacienne : mise en perspective », Labyrinthe [En ligne], 6 | 2000, mis en ligne le 20 mars 2005, consulté le 01 mai 2019. URL : http://journals.openedition.org/labyrinthe/410 DOI : 10.4000/labyrinthe.410

Ce document a été généré automatiquement le 1 mai 2019.

Propriété intellectuelle 


\title{
L'héraldique balzacienne: mise en perspective
}

\author{
Laurent Ferri
}

Résumé d'une thèse d'École des chartes rédigée
sous la direction de MM. Pastoureau et Leniaud, et
soutenue en mars 1999 devant un jury comprenant
MM. Bercé, Fossier, Pastoureau et Pierrot (un
exemplaire dactylographié est consultable aux

Archives nationales).

1 Depuis quelques années, l'héraldique sort des ornières généalogiques ou ésotériques pour redevenir, à part entière, une science auxiliaire de l'histoire, discipline élargie à l'étude des représentations et de l'imaginaire collectifs. Le terrain d'enquête le plus riche ouvert par l'héraldique nouvelle, incarnée par Michel Pastoureau, est certainement celui des armoiries imaginaires, c'est-à-dire celles des personnages de fiction, principalement romanesques. Certes, les corpus les plus abondants se trouvent dans la littérature médiévale. Mais des œuvres plus récentes, comme La Comédie humaine de Balzac invitent, elles aussi, au défrichement et au déchiffrement. Délaissée, en effet, par une critique spécialisée surabondante, encore accrue par les publications du Bicentenaire de la naissance de l'écrivain (1999), la dimension héraldique des romans participe pleinement de la dimension démiurgique du projet balzacien. Mais, en outre, elle permet de croiser l'individuel (les préoccupations nobiliaires et l'engagement légitimiste de Balzac après 1830) et le collectif (l'héraldique ressortissant au renouveau des noblesses mais aussi au goût universel pour un Moyen Âge " troubadour »), l'humain (avec ses vanités) et le livresque (car en blasonnant, le roman manifeste la capacité de l'écrivain à manier « tous les styles » et pour le coup, gagne ses « lettres de noblesse »).

2 Il convient dans un premier temps d'inscrire le phénomène à l'horizon collectif de la civilisation de la première moitié $\mathrm{du} \mathrm{XIX}^{\mathrm{e}}$ siècle. La Comédie humaine témoigne de l'« efflorescence héraldique » (E. Bouyé) que connaît cette époque. 
3 La Révolution française avait condamné les armoiries au nom de l'égalité républicaine, quoiqu'elles ne soient pas en France, juridiquement du moins, un privilège de l'aristocratie. Un vandalisme antihéraldique polymorphe se déchaîne entre 1792 et 1795, qui marque irréparablement le paysage urbain en faisant disparaître les décors armoriés des façades, et condamne de nombreux documents d'archives, par exemple. L'héraldique familiale entre en sommeil, jusqu'au Consulat. Réapparaît alors sa fonction sociale, qui est d'agir comme une marque de distinction. Au sein des classes (le concept est inventé par Guizot), les castes renforcent des pratiques à fonction identitaire. Un tour d'horizon permet, dans cette perspective, de découvrir des usages très variés aux écussons. Toute redéfinition de l'aristocratie (et plus que jamais, entre 1789 et 1914, l'Histoire est « le cimetière des élites ", pour reprendre la formule de Pareto), s'accompagne de la création d'un nouveau système héraldique (ainsi sous l'Empire), parfois d'un certain brouillage (ainsi sous la monarchie de Juillet). À côté de la fonction sociale, prend place la fonction politique de l'héraldique : en témoignent les passions autour du drapeau, tissu héraldique national. Enfin, on discerne une fonction artistique et patrimoniale : symboles du vandalisme, emblèmes du Moyen Âge et de la Renaissance, les armoiries permettent de ressusciter, parfois de façon superficielle, un cadre et une atmosphère "gothiques ". S'enracinant dans un passé nimbé de poésie, le blason offre aux peintres la facilité d'une estampille, aux poètes les séductions de l'ésotérisme et du beau langage. Aucune des fonctions n'a échappé à Balzac.

4 L'état des apprentissages montre l'importance du fait héraldique dans la société qu'il décrit. On distingue l'héraldique des gens du monde (servant pour la correspondance, la conversation et l'identification sociale, les armoriaux tenant lieu de Bottin mondain), l'héraldique des savants (Jules Quicherat, professeur à l'École des chartes, ouvrant la voie), enfin une héraldique " grand public », les manuels de blason aux tirages étonnants apparaissant autant comme des livres à rêver que comme des ouvrages didactiques.

Le phénomène ressortit, deuxièmement, à l'horizon biographique : Balzac, homme du monde, personnage littéraire à lui seul et créateur, se passionne pour l'héraldique.

6 Les armoiries personnelles renvoient certes aux prétentions à la noblesse, tenues du père de l'écrivain, et renforcées par la fréquentation de grandes dames qui sont parfois ses maitresses ( $\mathrm{M}^{\mathrm{me}}$ de Castries), ou de figures du parti romantico-légitimiste (Alcide de Beauchesne, féru d'héraldique littéraire, qui forge pour notre homme des armoiries précisément imitées de celles des Balzac d'Entragues). Pourtant, il ne s'agit pas que d'un hobby au service de la gloriole mondaine. Balzac comprend vite l'intérêt publicitaire de ses armoiries, et en fait une pièce maîtresse de la création de son personnage littéraire, notion essentielle de la modernité comme l'a bien vu Baudelaire.

7 De surcroît, l'héraldique est fondamentale au sein de la vision qu'a l'écrivain de la société et du roman. Il l'utilise comme ressort dramatique, comme support de dénonciation d'une société des faux-semblants, et, via la métaphore insistante de la tache sur le blason, elle renvoie à l'obsession balzacienne de la souillure morale qui accompagne toute ascension sociale. Il en fait une pièce maîtresse de sa composition, l'effet d'érudition servant nécessairement l'historien des mœurs contemporaines qu'il veut être : l'héraldique devient une science auxiliaire du roman.

8 Comment, enfin, ne pas envisager pour l'héraldique l'horizon romanesque ? Elle est pleinement un fait d'écriture. 
9 Étudier l'héraldique à l'œuvre, c'est d'abord rappeler les étapes de son introduction : dans un premier temps, nous trouvons des passages héraldiques isolés (Les Chouans, 1829 ; Les Employés, 1837 ; Beatrix, 1838), qui ne satisfont pas Balzac. C'est pourquoi il se décide à systématiser et rationaliser l'entreprise. Il s'adjoint les services de Ferdinand de Gramont, son secrétaire (et peut-être plus), qualifié de « nouveau d'Hozier » pour avoir composé un armorial (1839) où les préoccupations symboliques et stylistiques l'emportent de loin sur la rigueur syntaxique (ce que n'a pas su voir un érudit comme Lot). Le travail de Gramont est complété par celui de la comtesse Ida de Bocarmé, une Belge mélancolique, groupie éperdue, qui donne de L'Armorial de la Comédie humaine une version aquarellée (1843). Les deux précieux documents, conservés à la Bibliothèque de l'Institut, méritent de figurer au premier plan des matériaux préparatoires de la somme balzacienne, au même titre que les carnets de notes documentaires ou les manuscrits.

10 Cela dit, le génie propre du Tourangeau est d'intégrer parfaitement les passages blasonnés, obéissant à une poétique très singulière et complexe, ainsi que toute la thématique héraldique, sans effet d'étrangeté ou d'incongruité. Si l'héraldique fait corps avec le reste du texte, c'est grâce à une série d'effets d'annonce, d'insertions, de développements qu'il faut analyser. C'est surtout parce que son utilité finit par être incontestable pour comprendre la sociologie et la psychologie des personnages.

11 Toute réduction de l'héraldique balzacienne à une psychologie (supposée) de parvenu ou aux idées " passéistes » de Balzac est dommageable. Elle ignore son importance dans la culture et la société de l'Empire, de la Restauration et de la monarchie de Juillet, dont l'auteur de La Comédie humaine s'est voulu l'historien critique. Elle passe à côté de faits d'écriture essentiels, qu'il s'agisse d'effets programmatiques, narratifs ou stylistiques. Espérons pour terminer que, mieux comprises, les armoiries imaginaires imaginées par l'auteur de Ferragus seront pour le lecteur une source de plaisir accru. 